\title{
Primer reporte de Boeremia exigua, como patógeno causante de la enfermedad de Derrite, en plantaciones de café (Coffea arabica variedad geisha) en tierras altas de Panamá.
}

\section{Núñez, Marlon}

Universidad de Panamá, Programa de Maestría en Microbiología Ambiental, convenio No. 68-2017,

SENACYT-UP.

Panamá, Panamá

m.nunez.microbiology@gmail.com

Mejía, Luis

Centro de Biodiversidad y Descubrimiento de Drogas, Instituto de Investigaciones Científicas y Servicios de Alta Tecnología (INDICASAT - AIP)

Panamá, Panamá

LMejia@indicasat.org.pa

\section{Abstract}

In the early 2018 rainy season, we observed lesions characterized by terminal death of branches and chlorosis in leaves, brown spots, all of this consistent with Derrite lesions on Coffea arabica plants geisha variety, on coffee farms in the highlands of Chiriquí, Panama, in the districts of Boquete and Volcan.

Based on morphology, DNA sequencing, and pathogenicity tests, the causal pathogen was identified as Boeremia exigua, which is the first report on C. arabica in Panama.

Keywords: Boeremia, Coffe, Derrite, Plant, Disease

\section{Resumen}

A principios del año 2018, durante la estación lluviosa, se observaron lesiones de presunta enfermedad de Derrite en plantas de café (Coffea arabica) variedad geisha, en los distritos de Boquete y Volcán de la provincia de Chiriquí.

Estas lesiones mostraban muerte descendente en ramas terminales y clorosis en las hojas, con manchas marrones descendiendo de la rama principal a las secundarias.

Se realizaron giras de campo para la toma de muestras y se llevaron al laboratorio, y en base a la morfología, la secuenciación de ADN, y pruebas de patogenicidad, se identificó como agente causal al hongo Boeremia exigua, siendo este, el primer reporte de éste patógeno 
sobre C. arabica variedad geisha en Panamá.

Palabras claves: Boeremia, Café, Derrite, Planta, Enfermedad

\section{INTRODUCCIÓN.}

Estudios económicos muestras que la industria del café en Panamá aporta un valor agregado de 212.2 millones de balboas, lo que representa el $0.4 \%$ del Producto Interno Bruto (PIB) del país. Aparte generan más de 74 millones de Ingresos en ventas, lo que hace un gran total de 397 millones de balboas, que contribuyen a la economía nacional sólo en café tostado, sin contar el aporte a las comunidades aleñadas, en oportunidad de empleos por la mano de obra que contratan de forma permanente y eventual en su producción [1]. Dentro de este rubro, existe una estimación especial para la producción de café geisha en el País; producto que tiene un récord histórico en la venta de 454 gramos en 1,300.50 balboas en 2020 [2].

Al comienzo de la estación lluviosa en junio de 201, los agricultores comenzaron a dar testimonio de la aparición de síntomas de enfermedad en una plantación de café en Boquete, que parecía ser muerte descendente, quema o "derrite". Estas observaciones fueron seguidas por nosotros visitando las localidades. Los síntomas y análisis de las muestras se describen en este trabajo.

El derrite del café, es una enfermedad que se desarrolla a partir de 1400 metros sobre el nivel del mar (msnm), con una temperatura de $20^{\circ}$ Celsius, y un mínimo de 6 horas de luz, las hojas muestran signos de marchitamiento progresivo del tejido suculento de brotes terminales descendente por el tallo principal, hacia las ramas laterales [3]. En 1957, se hizo el primer reporte sobre la enfermedad de Derrite en Centroamérica; identificando el agente causal como Phoma costarricenses [4]; en resienten años, se informó de la presencia de $P$. Costarricenses, causando la enfermedad de derrite en café, en plantaciones que están por encima de los 1400 msnm, en Costa Rica [5].

Phoma es uno de los tres géneros principales dentro de la familia Didymelaceae, con más de 5.400 registros de taxones en el micobank [6]. Se ha informado que el género Phoma es altamente polifilético con especies similares a Phoma presentes en al menos seis familias dentro del orden de los Pleosporales. Para acomodar morfológicamente a todas esas especies similares a Phoma, se estableció el género Boeremia [7], los integrantes de este 
género han sido reportados como patógenos de un gran número de familias de plantas, dentro de las que podemos mencionar la familia Amaryllidaceae, Apocynaceae, Araliaceae, Caprifoliaceae, Chenopodiaceae, Crassulaceae, Fabaceae, Lamiaceae, Linaceae, Oleaceae, Rubiaceae, Salicaceae, Solanaceae, Ulmaceae y Umbelliferae [8]

\section{MATERIALES Y MÉTODO}

\section{A. Giras de Campo y aislamiento del Patógeno.}

Se realizaron dos giras de recolección al distrito de Boquete el 16/08/2019 y 19/10/2019, y una gira al distrito de Volcán el 18/11/2019, donde se recolectaron muestras de hojas de plantas de café, Coffea arabica variedad geisha con síntomas de la enfermedad (Fig.1 A-C).

Se colocaron en bolsas plásticas y se transportaron refrigeradas con hielo en una hielera al laboratorio donde fueron procesadas; Las muestras se lavaron con agua del grifo y luego se cortaron trozos de tejido con síntomas en cuadrados de $2 \mathrm{~mm}$ para su procesamiento; se desinfectaron por inmersión en una solución de etanol al 70\% durante 2 minutos y luego en una solución de hipoclorito de sodio al $0.03 \%$ durante tres minutos, y se colocaron en agar extracto de malta al $2 \%$ ( $2 \%$ MEA), 16 piezas por plato petri y se cultivaron a temperatura ambiente $\left(22-23^{\circ}\right.$ Celsius $)$.

Los hongos que crecían a partir de los trozos de tejido lesionado, después de cinco días de crecimiento, se transfirieron a nuevos platos de 2\% de MEA. Pasados siete días de crecimiento, se foto-documentó la morfología del estadio anamorfo. Entre las 3 giras, se realizaron un total de 96 Aislamientos, observándose una misma morfología predominante, en ambos sitios de muestreó. Seleccionamos al individuo DE46 como representante de la morfología predominante en el área de Boquete y el individuo DE86 como el representante de la morfología predominante aislado de las muestras del distrito de Volcán (Fig. 01 D-G)

\section{B. Biología Molecular}

Un (1) cm cuadrado de micelio activo fue tomada de los platos con siete días de crecimiento y se procesaron con el kit de extracción de ADN Gentra Puregene (QIAGEN, Alemania) siguiendo las instrucciones del fabricante.

Posteriormente, se realizó una PCR de punto final, amplificando la región interespacial ITS con cebadores ITS4, ITS5 (Blanco et al. 1990), y el gen que codifica para la subunidad ribosómica grande (LSU) de forma parcial con los cebadores P2, LR3, LR5 y LR7 (Guadet et al. 1989 ; Vilgalys y Hester 1990) bajo las siguientes condiciones: 25 ul de volumen total para la reacción, que contienen 5-15 ng de ADN genómico, $200 \mathrm{mM}$ de cada dNTP, 2,5 unidades de Taq ADN polimerasa (QIAGEN, Alemania), $2 \mathrm{mM}$ de cada cebador y tampón 10x con 
MgCl2 15mM; se utilizó el termociclador iCycler ABI 2720 (Applied Biosystems, EE.UU.) El ciclado térmico programado para la región ITS fue el siguiente: $5 \mathrm{~min}$ a $94^{\circ} \mathrm{C}, 35$ ciclos de $45 \mathrm{~s}$ a $94^{\circ} \mathrm{C}, 30 \mathrm{~s}$ a $50^{\circ} \mathrm{C}, 10,5 \mathrm{~min}$ a $72^{\circ} \mathrm{C}$, y un período final de extensión de 10 min a $72^{\circ} \mathrm{C}$. El programa del termociclador para la región LSU fue el siguiente: 8 min a $95^{\circ} \mathrm{C}, 35$ ciclos de $15 \mathrm{~s}$ a $95^{\circ} \mathrm{C}, 20 \mathrm{~s}$ a $55^{\circ} \mathrm{C}, 1 \mathrm{~min}$ a $72^{\circ} \mathrm{C}$ y un período de extensión final de $5 \mathrm{~min}$ a $72^{\circ} \mathrm{C}$.

Los amplicones se purificaron con el Kit ExoSAP-IT (USB, Cleveland, EE.UU.) Siguiendo el protocolo del fabricante; el ADN purificado se utilizó en un nuevo ciclo de reacciones de secuenciación utilizando el kit BigDye Terminatorv 3.1 (Applied Biosystems, Life Technologies Corporation, Carlsbad CA). El producto de esa reacción final se purificó utilizando el kit Big Dye Xterminator y posteriormente se secuenció con un analizador genético Applied Biosystems 3500 (Life Technologies, Carlsbad, CA).

Un análisis de alineamiento con la herramienta BLAST reveló $99.82-100 \%$ de identidad con las secuencias de Boeremia sp. para el aislamiento DE46 y $99,63-99,82 \%$ de identidad con secuencias de Boeremia exigua para el aislamiento DE86, con la secuencia ITS ambos aislamientos coincidieron en un $\mathbf{9 9 . 7 1 \%}$ de identidad con Boeremia exigua. Finalmente se construyó un árbol filogenético concatenado con las secuencias de ambos marcadores ITSxLSU utilizando el software libre MegaX64 (Fig. 02)

\section{Prueba de Patogenicidad}

Un ensayo de patogenicidad se llevó a cabo en hojas desprendidas de Coffea arabica, variedad geisha; Se cortaron discos de agar con micelio en crecimiento activo del margen de un cultivo de 7 días en MEA al 2\% de los hongos aislados DE46 y DE86. Los discos se pusieron en contacto con el reverso de hojas sanas desprendidas; en la lámina izquierda, entre las venas secundarias, específicamente se colocaron dos discos de MEA al $2 \%$ por el lado del micelio, con 50 uL de agua esterilizada, y se colocaron dos discos de MEA al $2 \%$ sin micelio en la lámina derecha, entre las venas secundarias y encima 50 ul de agua esterilizada (controles). Se inocularon cuatro hojas por cepa para un total de 8 puntos de contacto. Las hojas experimentales se colocaron dentro de una caja de plástico transparente con dimensiones de $45 \times 75 \times 25 \mathrm{~cm}$ y esta se colocó dentro de una cámara de crecimiento vegetal (BIOBASE, Shandong, China) que tenía los siguientes parámetros ambientales 12 horas de luz al $40 \%$ de intensidad, 12 horas de oscuridad, a $24^{\circ} \mathrm{C}, 60 \%$ de humedad relativa. Se incluyó un hongo endófito de la familia Didymelaceae, Didymella sp (CA1235), en igualdad de condiciones como un control adicional (Fig. 03)

\section{RESULTADOS}




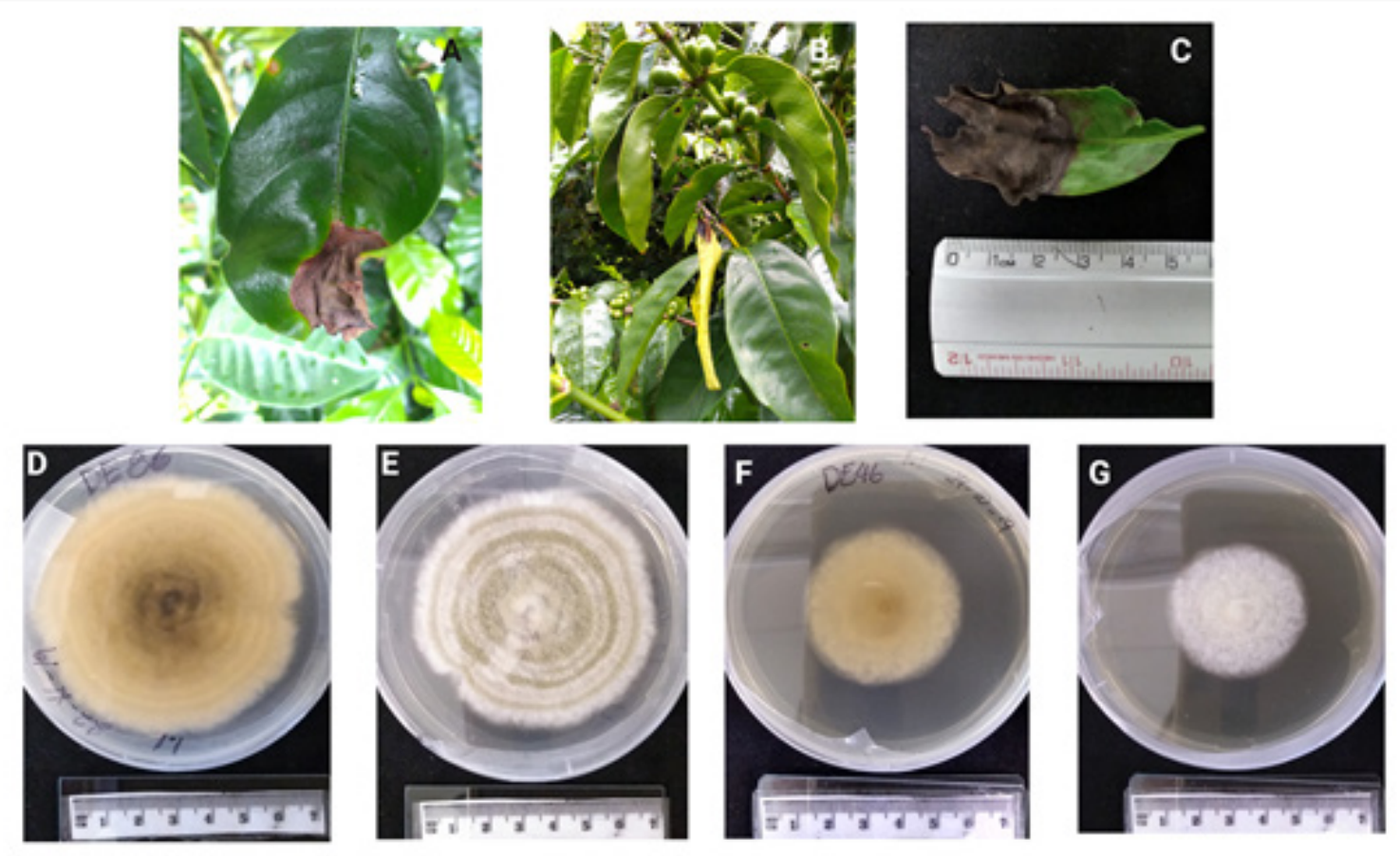

Fig. 01. Lesiones de Derrite en plantas de Café. A: Lesión en hoja en campo. B: Lesión en brote de rama en campo. C. Hoja en laboratorio. Morfología de hongos aislados. D-E Hongo aislado del distrito de Volcán, F-G Hongo aislado del distrito de Boquete. 


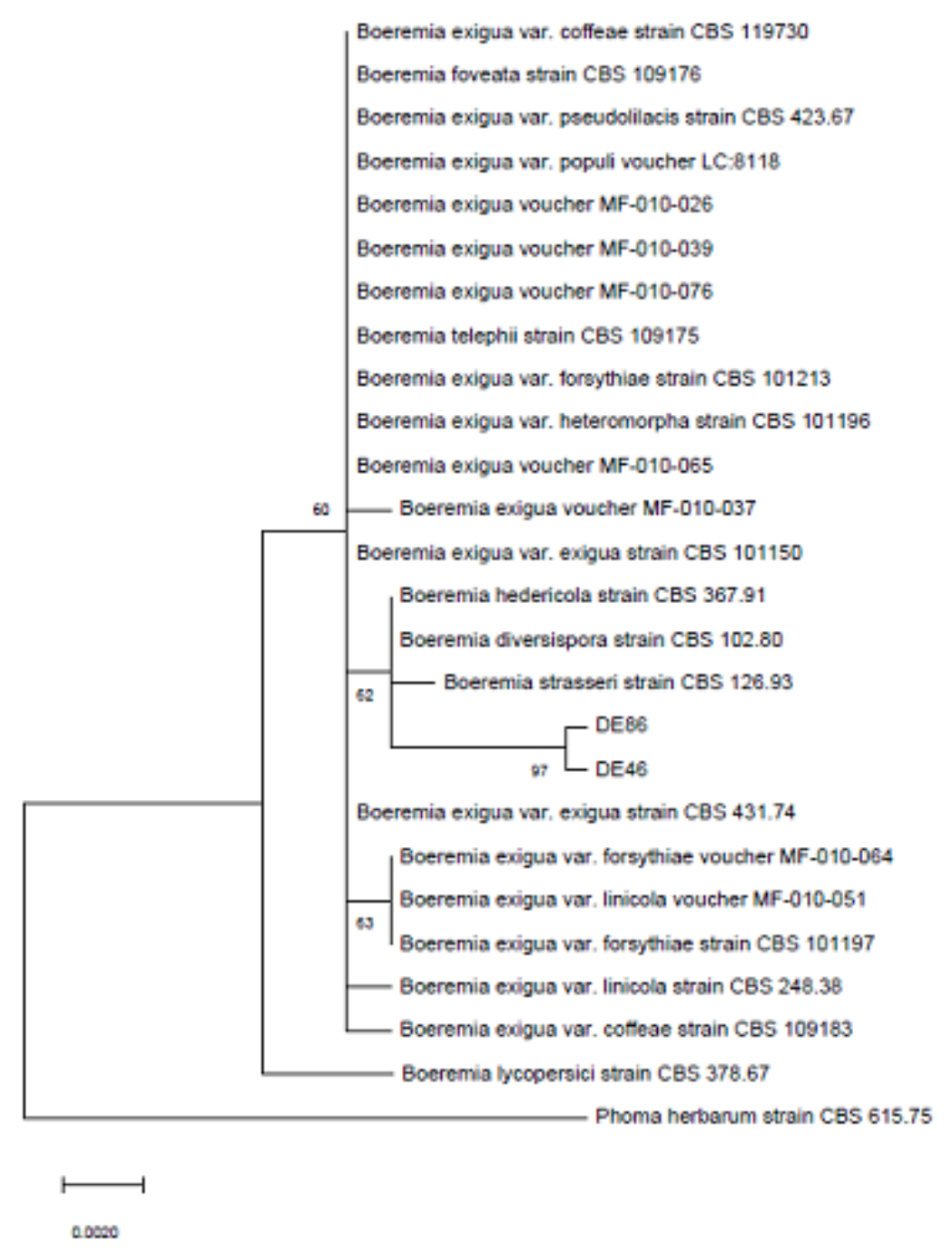

Fig. 02. Análisis de máxima verosimilitud; los árboles iniciales para la búsqueda heurística se obtuvieron automáticamente aplicando los algoritmos Neighbour-Join y BioNJ a una matriz de distancias por pares estimadas utilizando el enfoque de máxima probabilidad compuesta (MCL). Se utilizaron alineamientos concatenados de secuencias de nucleótidos de ADN de los marcadores ITS y LSU. Se indicaron valores de soporte de Bootstrap de 10,000 réplicas en los nodos respectivos. El árbol se enraizó con Phoma herbarum como grupo externo; se utilizó el software libre Mega X64. 


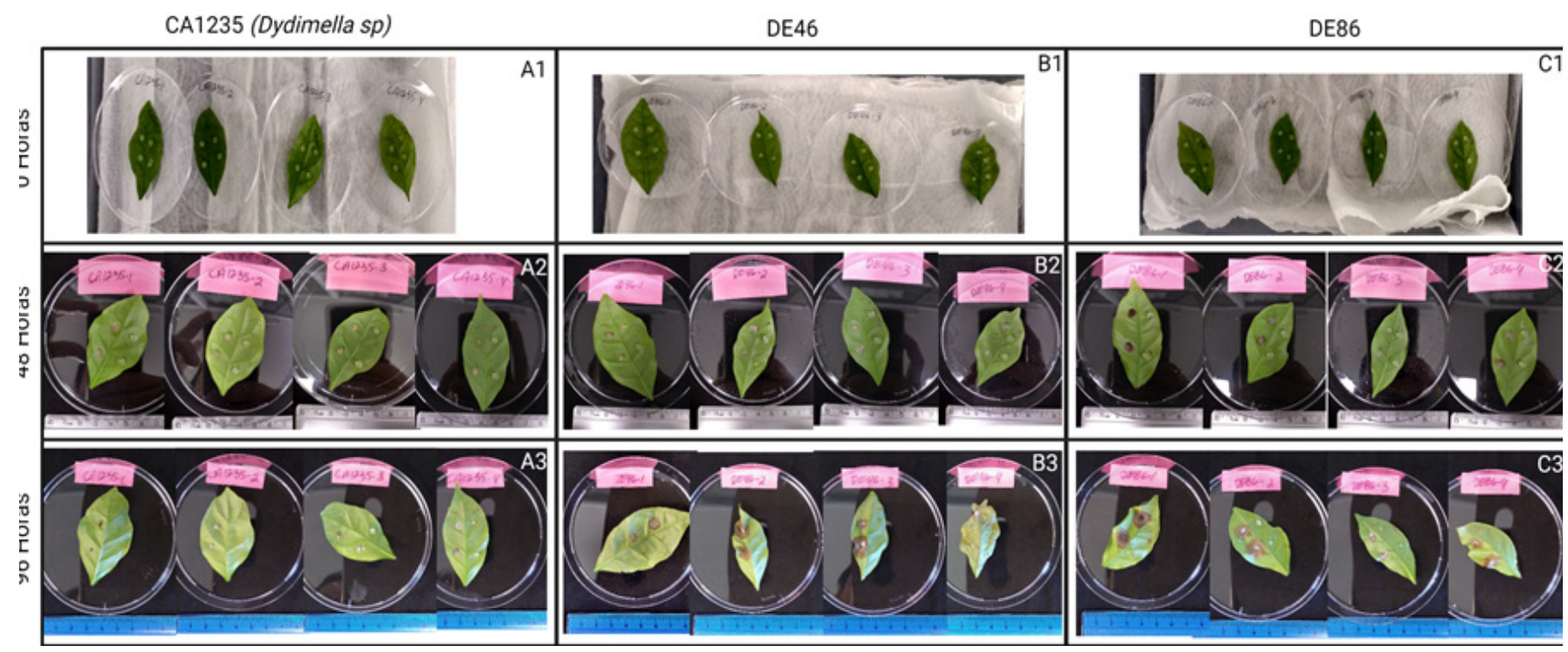

Fig.03. Prueba de patogenicidad en hojas de Coffea arabica variedad geisha. A1 Hongo endófito del café, Dydimella sp, 0 horas. A2 Hongo endófito del café, Dydimella sp, 48 horas. A3. Hongo endófito del café, Dydimella sp, 96 horas. No se observan lesiones causadas por el hongo ni por los discos de agar control. B1. Hongo aislado DE46 0 horas. B2 Hongo aislado DE46 48 Horas. B3 Hongo aislado DE46 96 horas. C1. Hongo aislado DE86 0 Horas. C2 Hongo aislado DE86 48 Horas. C3. Hongo aislado DE86 96 Horas. Se puede observar la aparición de lesiones similares a Derrite en las hojas, por parte de ambos hongos aislados, DE46 y DE86. No se observan lesiones por los discos de agar control.

\section{CONCLUSIONES}

El agente causal de la enfermedad de Derrite en cultivos de café de altura (Coffea arabica) variedad geisha en los distritos de Volcán y Boquete; es el mismo individuo según podemos ver en el árbol filogenético concatenado, utilizando las regiones ITS y LSU. Este es el hongo Boeremia exigua, miembro de la familia Dydimellaceae. Existen reportes de este individuo como patógeno de café en otros países, sin embargo, no existen reportes de este hongo como patógeno en Panamá, siendo este su primer reporte preliminar.

\section{Referencias}

[1] Comisión de Asuntos Agropecuarios, Sección 0815-01603 Panamá, 2019

[2] Redacción mi diario. 'Café Panameño rompe record de ventas'. 18 de septiembre de 2020.

[3] G-V. Luis and L-C Jairo. "La muerte descendente del Cafeto". CENICAFÉ, Avances Tec. 278. 2010.

[4] E. Eddie. 'La Quema de los cafetos causada por Phoma costarricensis nsp'. Rev. Biol. Trop. 5 ( 1 ) :81102. 1957.

[5] M. Barquero, A. Robles, M. Hidalgo, M. Chacon, A. Gamboa. 'Aggressiveness of Phoma and 
Colletotrichum Isolates in Los Santos Region of Costa Rica'. 2014.

[6] C. Pedro, G. Walter, s. Joost, R. Vincent and S. 'MycoBank: an online initiative to launch mycology into the 21st century'. STUDIES IN MYCOLOGY 50: 19-22. 2004.

[7] M. Aveskamp, J. de Gruyter, J. Woudenberg, G. Verkley and P. Crous, 'Highlights of the Didymellaceae: A polyphasic approach to characterise Phoma and related pleosporalean genera'. Studies in Mycology 65: 1-60. 2010.

[8] Q. Chen, L.W. Hou, W.J. Duan, P.W. Crous, and L. Cai. 'Didymellaceae revisited'. STUDIES IN MYCOLOGY 87: 105-159. 2017.

\section{Autorización y Licencia CC}

Los autores autorizan a APANAC XVIII a publicar el artículo en las actas de la conferencia en Acceso Abierto (Open Access) en diversos formatos digitales (PDF, HTML, EPUB) e integrarlos en diversas plataformas online como repositorios y bases de datos bajo la licencia CC:

Attribution-NonCommercial-ShareAlike 4.0 International (CC BY-NC-SA 4.0) https://creativecommons. org/licenses/by-nc-sa/4.0/.

Ni APANAC XVIII ni los editores son responsables ni del contenido ni de las implicaciones de lo expresado en el artículo. 